\title{
Changes in allergenicity of ovalbumin in vitro and vivo on conjugation with quercetin
}

Tingting Zhang, Zongyi Hu, Yongwei Cheng, Haoxie Xu, Tanja Cirkovic Velickovic, Kan He, Fan Sun, Zhendan He, Zhigang Liu, and Xuli Wu

J. Agric. Food Chem., Just Accepted Manuscript • DOI: 10.1021/acs.jafc.0c00461 • Publication Date (Web): 17 Mar 2020

Downloaded from pubs.acs.org on March 18, 2020

\section{Just Accepted}

"Just Accepted" manuscripts have been peer-reviewed and accepted for publication. They are posted online prior to technical editing, formatting for publication and author proofing. The American Chemical Society provides "Just Accepted" as a service to the research community to expedite the dissemination of scientific material as soon as possible after acceptance. "Just Accepted" manuscripts appear in full in PDF format accompanied by an HTML abstract. "Just Accepted" manuscripts have been fully peer reviewed, but should not be considered the official version of record. They are citable by the Digital Object Identifier (DOI®). "Just Accepted" is an optional service offered to authors. Therefore, the "Just Accepted" Web site may not include all articles that will be published in the journal. After a manuscript is technically edited and formatted, it will be removed from the "Just Accepted" Web site and published as an ASAP article. Note that technical editing may introduce minor changes to the manuscript text and/or graphics which could affect content, and all legal disclaimers and ethical guidelines that apply to the journal pertain. ACS cannot be held responsible for errors or consequences arising from the use of information contained in these "Just Accepted" manuscripts. 


\section{Changes in allergenicity of ovalbumin in vitro and vivo on conjugation with quercetin}

Tingting Zhang a , Zongyi Hu ${ }^{\text {a,b }}$,Yongwei Cheng a, c, Haoxie Xu a, Tanja Cirkovic Velickovic $^{\text {d, f }}$, Kan $\mathrm{He}^{\text {a }}$, Fan Sun ${ }^{\text {a }}$, Zhendan $\mathrm{He}^{\text {a }}$, Zhigang Liu ${ }^{\text {a }}$, Xuli Wu ${ }^{\text {* }}$

a School of Public Health, Health Science Center, Shenzhen University, Shenzhen, Guangdong Province, PR China, 518060

${ }^{\mathrm{b}}$ Department of Anesthesiology, Shenzhen Nanshan Maternity and Child healthcare Hospital, Shenzhen, Guangdong Province, PR China, 518060

c Department of Obstetricians and Gynaecologists, Shenzhen University General Hospital, Shenzhen, Guangdong Province, PR China, 518060

${ }^{\mathrm{d}}$ Center of Excellence for Molecular Food Sciences \& Department of Biochemistry, University of Belgrade-Faculty of Chemistry, Belgrade, Serbia

${ }^{\text {f}}$ Ghent University Global Campus, Incheon, South Korea

${ }^{*}$ Corresponding author:

School of Public Health, Health Science Center, Shenzhen University

Nanhai Ave 3688, Shenzhen, Guangdong, P.R. China 518060

Tel: +86 755 86671909; Fax: +86 75586671906 ;

E-mail addresses: wxl@szu.edu.cn

Tingting Zhang and Zongyi Hu contributed equally to this work. 


\section{ABSTRACT}

Previous study demonstrated decreased allergenicity in vitro of some food allergens after conjugation with polyphenols. However, little is known about how polyphenol conjugation with food allergens affects in vivo allergenicity. We conjugated a well-known food allergen, ovalbumin (OVA), with quercetin (QUE) to assess the potential allergenicity of OVA in vitro and in vivo in a BALB/c mouse model. QUE could covalently conjugate with OVA and changed the protein structure, which might destroy and/or mask OVA epitopes. Conjugation with QUE decreased IgE-binding properties and the release capacity of the conjugated OVA. In vivo, as compared with native protein, conjugation with QUE decreased the levels of IgE, IgG1, IgG, plasma histamine and mast cell protease-1 (mMCP-1) on the surface of sensitized mast cells, along with decreased FceRI ${ }^{+}$and c-kit ${ }^{+}$expression. The levels of Th2-related cytokines (IL-4, IL-5, IL-13) decreased and that of a Th1-related cytokine (IFN- $\gamma$ ) increased slightly, which suggests that conjugation with QUE modulated the imbalance of the Th1/Th2 immune response. Conjugation of OVA with QUE could reduce OVA allergenicity in vitro and in vivo, which could provide information for reducing food allergenicity by conjugation with polyphenols.

KEYWORDS: OVA, Quercetin, Conjugation, Allergenicity, Mouse model 


\section{INTRODUCTION}

Food allergy is an important public health issue and affects about $8 \%$ of children and $5 \%$ of adults, with increasing incidence in the past few years ${ }^{1}$. Egg allergy is one of the most common food allergies, particularly in children under the age of $3^{2}$.

Ovalbumin (OVA, $45 \mathrm{kDa})$ is one of the major allergens in egg causing IgE-mediated allergic reactions, the most frequent. Processing techniques for destroying the allergenicity of OVA in egg white have wide interest ${ }^{3}$. Among the potential alteration methods, the interaction between polyphenols and allergens can reduce allergenicity by changing the protein structure or rendering the allergen less bioavailable ${ }^{4}$.

Polyphenols can bind protein by non-covalent and covalent interaction ${ }^{5,6}$. A number of studies have investigated the interaction between polyphenols and food allergens. Polyphenol interactions can reduce the immunogenicity and allergenicity of wheat gliadins ${ }^{7}$. Caffeic, chlorogenic acids and ferulic can bind to Ara h1 and Ara h2, which reduces the IgE binding of the protein ${ }^{8}$. The IgE-binding capacity of the major cherry allergen Pru av 1 was reduced after interaction with gallic acid, quercetin and epicatechin ${ }^{9}$. Previous studies have found reduced IgE-binding and degranulation capacities of peanut flour after interaction with polyphenolic extracts rich in pro-anthocyanidins and anthocyanins ${ }^{10-12}$. Furthermore, an in vivo study demonstrated that complexation of polyphenols to peanut flour inhibited specific IgE antibody production in peanut-sensitized mice ${ }^{13}$. Our previous report of the reduced IgE- and IgG-binding activities of $\beta$-lactoglobulin after catechin binding supports the 
above findings ${ }^{14}$. Considering these findings, interaction with polyphenols might be a potential novel strategy for producing hypoallergenic food. Non-covalent binding of epigallo-catechin 3-gallate (EGCG) to OVA resulted in structural changes in protein. However, EGCG did not prevent the IgE-OVA interaction ${ }^{15}$. As compared with covalent interactions between polyphenols and proteins, non-covalent interactions are reversible, with lower affinity ${ }^{16}$, which suggests that reducing the allergenicity of food allergen by non-covalent interactions is limited in food processing. We have investigated the effect of covalent interactions with polyphenols on the allergenic capacity of OVA. After conjugation with polyphenols, the IgE-binding of OVA decreased, with increased emulsifying and foaming properties, antioxidant activity and digestibility ${ }^{17-18}$. However, whether covalent conjugation with polyphenols can reduce the allergenic properties of OVA needs to be confirmed by in vivo studies.

Quercetin (QUE) is a common dietary polyphenol in many plant foods. In this study, we prepared OVA-polyphone conjugates by covalent interaction with QUE and investigated the covalent interaction and structural changes. The changes in allergenicity of OVA in vitro were evaluated by IgE-binding capacity and human basophil leukemia (KU812) cell degranulation assay. Furthermore, we used a mouse model of orally induced OVA allergy to evaluate the allergenicity of OVA after conjugation with QUE in vivo, which could provide pre-clinical data for the development of innovative hypoallergenic food products. 
64

65

66

67

68

69

70

71

72

73

74

75

\section{MATERIALS AND METHODS}

\section{Materials}

OVA (protein content $>98 \%$ ), QUE (purity $\geq 95 \%$ ),

1,10-diphenyl-2-picrylhydrazyl (DPPH), Folin-Ciocalteau phenol reagent, 3,3'-5,5'tetramethylbenzidine (TMB) and

2,2-azinobis(3-ethylbenzthiazoline)-6-sulfonic acid (ABTS) were from Sigma-Aldrich (St. Louis, MO, USA). Mouse IgG-antihuman IgE antibody and

NeutrAvidin-HRP-conjugated antibody were from SouthernBiotech (Birmingham, AL, USA). Horseradish peroxidase (HRP)-conjugated goat anti-human IgE was from Kirkegaard \& Perry Laboratories (Gaithersburg, MD, USA).

Serum samples from 12 children who were allergic to OVA were generously provided by Shenzhen Children's Hospital (Guangdong, China), and the availability was approved by the human ethics committee of Health Science Center at Shenzhen University (Permit No. 201606016). Each individual signed an informed consent. All anti-OVA-specific IgE levels in serum samples were $>10 \mathrm{kU} / \mathrm{L}$. Pooled normal serum samples from individuals $(n=5)$ without allergy to chicken egg were negative controls.

\section{Preparation of samples}

The OVA-QUE conjugates were prepared by the alkaline method or free radical method. To prepare conjugates by the alkaline method as described previously ${ }^{13}, 0.25$ g OVA was dissolved in $50 \mathrm{~mL}$ distilled $\mathrm{H}_{2} \mathrm{O}$ and the $\mathrm{pH}$ was adjusted to 9.0 , then 
samples were maintained at $25^{\circ} \mathrm{C}$ for $2 \mathrm{~h}$ under atmospheric air. A 0.5 -mmol amount of QUE was added to the mixture with continuous stirring for $24 \mathrm{~h}$. The unreacted QUE was removed by dialysis at $4{ }^{\circ} \mathrm{C}$ for $48 \mathrm{~h}$ with Milli-Q water. The free radical method was performed as described ${ }^{19}$ with modification. After dissolving $0.5 \mathrm{~g}$ OVA in $50 \mathrm{~mL}$ distilled $\mathrm{H}_{2} \mathrm{O}, 1.0 \mathrm{~mL} 5.0 \mathrm{M} \mathrm{H}_{2} \mathrm{O}_{2}$ and $0.25 \mathrm{~g}$ ascorbic acid were added to the solution, then samples were maintained at $25^{\circ} \mathrm{C}$. After $2 \mathrm{~h}, 0.35 \mathrm{mmol}$ QUE was added to the solution and maintained at $25^{\circ} \mathrm{C}$ for $24 \mathrm{~h}$. Unreacted QUE was removed as described above. Finally, the conjugates were obtained by freezing and drying samples.

The contents of conjugates were detected by the Foline-Ciocalteu method as we previously described ${ }^{20}$, with QUE as a standard. Determining free amino groups in samples involved use of trinitro-benzene-sulfonic acid as previously described ${ }^{21}$. The contents of sulfhydryl thiol groups and tyrosine in samples were measured as we previously described ${ }^{19}$.

\section{SDS-PAGE}

SDS-PAGE was performed on a $5 \%$ stacking gel and $12 \%$ separating gel. A $10-\mu 1$ loading buffer (Solarbio Life Science, Beijing) was mixed with $40 \mu 1$ samples (1 $\mathrm{mg} / \mathrm{mL}$ ) and heated at $95{ }^{\circ} \mathrm{C}$ for $5 \mathrm{~min}$. Then aliquots were loaded on the gels. After staining with Coomassie Brilliant Blue R-250 for $0.5 \mathrm{~h}$, gels were destained with $7.5 \%$ acetic acid and 5\% methanol for $10 \mathrm{~h}$ and scanned. 
108

\section{Structural analysis of conjugates}

Fourier transform infrared (FTIR) spectroscopy

The FTIR spectra were detected as previously described ${ }^{22}$ by using a FTIR-8300PCS spectrometer (SHIMADZU Co., Kyoto, Japan) with KBr pellets. The samples were measured at $25{ }^{\circ} \mathrm{C}$ in the range of 400 to $4000 \mathrm{~cm}-1$ with 32 scans and $4 \mathrm{~cm}-1$ resolution.

\section{Circular dichroism (CD)}

CD was performed as previously described ${ }^{23}$. The ellipticity of samples $(0.015$ $\mathrm{mg} / \mathrm{mL}$ ) was recorded on a Jasco-810 spectrophotometer (Jasco Co., Japan) with resolution $0.2 \mathrm{~nm}$ and $100 \mathrm{~nm} / \mathrm{min}$ speed step in the range of $190-250 \mathrm{~nm}$ at $25{ }^{\circ} \mathrm{C}$.

\section{Differential scanning calorimetry (DSC)}

DSC was used to examine the thermal stability of samples by using a DSC-60 calorimeter (Shimadzu, Tokyo). A 5-mg sample was placed in an aluminum pan that was sealed tightly. Using nitrogen as the transfer gas at a rate of $30 \mathrm{~mL} / \mathrm{min}$, the thermal analyses were performed from 30 to $180^{\circ} \mathrm{C}$ with a constant rate of $5^{\circ} \mathrm{C} / \mathrm{min}$.

\section{In vitro allergenicity assessment}

Competitive inhibition of ELISA was used to measure the IgE-binding ability of samples.A-100 $\mu \mathrm{L}$ sample solution $(2 \mathrm{mg} / \mathrm{ml})$ was added to a $96-w e l l$ microplate and incubated overnight at $4{ }^{\circ} \mathrm{C}$. After a wash with phosphate buffered saline (PBS) 
130

131

132

133

134

135

136

137

138

139

140

141

142

143

144

145

146

147

148

149

150

containing $0.05 \%$ Tween-20 (PBST), plates were blocked with $2 \%$ fish gelatin in

PBST for $1 \mathrm{~h}$ at $37^{\circ} \mathrm{C}$, then washed with PBST. A 50- $\mu \mathrm{L}$ amount of serum pool from egg-allergic patients (diluted 1:200) was mixed with $50 \mu \mathrm{L}$ of sample solution and added to each well. After incubation for $1 \mathrm{~h}$, plates were washed. A $100-\mu \mathrm{L}$ amount of HRP-conjugated goat anti-human IgE antibody (1:10,000) was added to wells and incubated for $40 \mathrm{~min}$ at $37^{\circ} \mathrm{C}$. After a wash, $50 \mu \mathrm{L}$ substrate was added. The reaction was stopped by adding $50 \mu \mathrm{L} \mathrm{H}_{2} \mathrm{SO}_{4}(2 \mathrm{M})$, and absorbance at $450 \mathrm{~nm}$ was measured.

\section{Antioxidant activity analysis of OVA-QUE conjugate}

DPPH scavenging activity

DPPH scavenging activity of OVA and OVA-QUE conjugates was measured as previously described ${ }^{20}$. In brief, $2 \mathrm{~mL}$ DPPH was mixed with $2 \mathrm{~mL}$ sample $(0.5$ $\mathrm{mg} / \mathrm{mL}$ ). The mixture was stored in the dark for $1 \mathrm{~h}$. Finally, the absorbance at 517 nm was measured.

ABTS+ scavenging activity

ABTS + scavenging activity of OVA and OVA-CHA conjugates was performed as previously described ${ }^{20}$. In brief, $3 \mathrm{~mL}$ ABTS reagent was mixed with $1 \mathrm{ml}$ sample $(0.5 \mathrm{mg} / \mathrm{mL})$. The mixture was incubated for $1 \mathrm{~h}$ at $25^{\circ} \mathrm{C}$. Finally, the absorbance at $734 \mathrm{~nm}$ was measured. 
151

152

153

154

155

156

157

\section{Cell model analysis}

The immature prebasophilic cell line (KU812) was purchased from the Chinese Academy of Sciences (Shanghai). Cells were cultured and the contents of histamine and IL- 6 in cells were measured as described ${ }^{24}$ with little modification. The cells were maintained in IMDM (Gibco, Shanghai) supplemented with 1\% penicillinstreptomycin (100x stock; GibcoBRL, Grand Island, NY) and 5\% fetal bovine serum (FBS, Gibco, Australia) and cultured in a humidified atmosphere with $5 \% \mathrm{CO}_{2}$ at $37^{\circ} \mathrm{C} . \mathrm{KU} 812$ cells $\left(1 \times 10^{7}\right.$ cells $\left./ \mathrm{mL}\right)$ were pre-incubated with $100 \mu \mathrm{L}$ serum from egg-allergic patients $(\mathrm{v} / \mathrm{v}=5: 1)$. Normal serum was a negative control. After incubation for $24 \mathrm{~h}, 10 \mu \mathrm{L}$ protein sample $(5 \mathrm{mg} / \mathrm{ml})$ was added and incubated for $4 \mathrm{~h}$. After centrifugation, supernatant was collected to detect the contents of histamine and IL- 6 by using human histamine and human IL-6 ELISA kits (Elabscience Biotech, Wuhan, China).

\section{Animal model analysis}

Mice

All female BALB/c mice (5-6 weeks) were approved by SPF (Beijing)

Biotechnology. Animal experiments were carried out according to protocols approved by the Animal Care and Use Committee of Health Science Center of Shenzhen University (Permit No. 201711003). We used 40 female BALB/c mice in this study. Before experiments, mice were housed and fed an OVA-free dietary for least 1 week. All mice were divided into four groups: control (healthy mice without stimulation), 
173

174

175

176

177

178

179

180

181

182

183

184

185

186

187

188

189

190

191

192

193

194

OVA, and radical and alkaline OVA-QUE conjugate groups.

Oral sensitization and challenge of mice

Mice were sensitized orally with a lavage needle on days $0,7,14,21$ and 28 with $5 \mathrm{mg}$ native OVA dissolved in PBS, which was mixed with $15 \mu \mathrm{g}$ cholera toxin (Sigma-Aldrich, St. Louis, MO, USA) as an oral sensitization (Figure 4A). The mice of the control group were sensitized with $15 \mu \mathrm{g}$ cholera toxin dissolved in PBS, then challenged with PBS $(500 \mu 1)$ alone on day 35 . The other three mouse groups - OVA and radical and alkaline OVA-QUE — were orally challenged on day 35 with $20 \mathrm{mg}$ OVA or radical or alkaline OVA-QUE conjugate in $500 \mu 1$ PBS, respectively. After 1 $\mathrm{h}$, a validated anaphylactic scoring (Table 1) was used to determine the allergic or anaphylactic symptoms of mice. Then mice were euthanized and blood, peritoneal fluid and spleens were collected for measuring the following biomarkers.

\section{Determination of allergen-specific immunoglobulins (Ig)}

$\operatorname{IgE}, \operatorname{IgG}$ and $\operatorname{IgG}_{1}$ were determined by ELISA. In brief, $100 \mu 1$ of $6 \mathrm{mg} / \mathrm{mL}$ ELISA coating buffer ( $\mathrm{pH}$ 9.6) was added to 96-well plates and incubated overnight. Serum from each mouse group ( $\mathrm{n}=5 /$ group$)$ was pooled in equal volumes $(100 \mu \mathrm{l})$ before analyses. Each diluted serum sample (1:20 for specific $\operatorname{IgE}, 1: 8000$ for specific $\operatorname{IgG}$ and $\operatorname{IgG1}$ ) was added to plates. HRP-labeled goat anti-mouse $\operatorname{IgE}, \operatorname{IgG}$ and $\operatorname{IgG}_{1}$ (1:2000) antibodies (BD Pharmingen, Mississauga, ON, Canada) were added to determine the binding of $\operatorname{IgE}, \operatorname{IgG}$ and $\operatorname{IgG} 1$. Finally, o-phenylenediamine substrate 
195 (Sigma-Aldrich, St. Louis, MO, USA) was added for color development.

196

197

Detection of mouse mast cell protease-1 (mMCP-1) in serum

Serum was collected from mice ( $\mathrm{n}=5 /$ group) after 1 -h challenge. The content of mMCP-1 in serum was analyzed by using an mMCP-1 ELISA kit (Elabscience Biotech, Wuhan, China) in accordance with the manufacturer's instructions.

\section{Morphological structure of duodenum}

After 1-h challenge with OVA or radical and or OVA-QUE, 4 mice in each group were euthanized. A 4-cm segment of the duodenum was removed from the mice immediately, then fixed with $10 \%$ formalin, and processed by standard histological techniques. Samples sectioned at 5 - $\mu \mathrm{m}$ thickness were stained with eosin and hematoxylin. Finally, a light microscope (Nikon Ti Microscope, Japan) was used to observe the morphological structure of the small intestine.

\section{Cytokine analysis}

Individual spleens were aseptically removed from mice ( $n=6 /$ group). After gently grinding spleens by using a syringe plunger, the contents were passed through a $100-\mu \mathrm{m}$ nylon membrane cell strainer. After erythrocyte lysis, spleen cells were cultivated in complete medium (RPMI-1640 containing $2 \mathrm{mM} / \mathrm{L}$-glutamine, $10 \%$ fetal bovine serum, $25 \mathrm{mM}$ HEPES buffer, $100 \mathrm{mg} / \mathrm{mL}$ streptomycin and $100 \mathrm{IU} / \mathrm{mL}$ penicillin). Cells $\left(2 \times 10^{6} /\right.$ well $)$ were cultured in 48 -well plates for $72 \mathrm{~h}$ in the presence 
217

218

of OVA or radical or alkaline OVE-QUE conjugate $(50 \mu \mathrm{g} / \mathrm{ml})$. The supernatant was collected, then IL-4, IL-5, IL-13 and IFN- $\gamma$ contents were measured by using ELISA kits (Elabscience Biotech, Wuhan, China).

\section{Histamine levels in mouse plasma}

Plasma was collected from mouse blood ( $\mathrm{n}=5 /$ group) and centrifuged for $10 \mathrm{~min}$ at 4000 g. Plasma histamine was measured by using a histamine ELISA kit (Elabscience Biotech, Wuhan, China).

\section{Identification of peritoneal mast cells in mice}

After challenge, peritoneal mast cells were collected from mice ( $\mathrm{n}=6 /$ group). In the initial step, $5 \mathrm{ml}$ RPMI-1640 containing 10\% fetal bovine serum was injected into the mouse's peritoneal cavity. After the mouse's abdomen was massaged softly for 1 min, peritoneal fluid containing mast cells was collected. After centrifugation at $150 \mathrm{~g}$ for $10 \mathrm{~min}$, cells were suspended in flow cytometry staining buffer.

The expression of the IgE receptor (FceRI) and c-kit was detected in mast cells. After staining with APC-conjugated anti-mouse-FceRI antibody $(0.25 \mu \mathrm{g} / \mathrm{test}$, clone MAR-1, Biolegend, San Diego, CA) and PE-conjugated anti-c-kit antibody (0.06 $\mu \mathrm{g} /$ test, clone $2 \mathrm{~B} 8$, Biolegend, San Diego, CA) for $30 \mathrm{~min}$ in the dark at $4^{\circ} \mathrm{C}$, cells were washed twice with flow cytometry staining buffer before flow cytometry. 


\section{Statistical analysis}

All sample determinations were carried out in triplicate. All data are expressed as mean \pm SD. Differences were determined by using ANOVA and the Duncan least significant difference test. $\mathrm{P}<0.05$ was considered statistically significant.

\section{RESULTS AND DISCUSSION}

\section{Profile of the OVA-QUE conjugates}

The band of OVA was about $45 \mathrm{kD}$ after conjugation with QUE (Figure 1A). As compared with native OVA, the bands of radical and alkaline OVA-QUE conjugates migrated up, which suggested that conjugation with QUE increased the molecular weight of OVA. The polyphenol content of radical and alkaline OVA-QUE was increased (Table 2), which suggests the conjugation of OVA with QUE.

The content of thiol groups was decreased in OVA with QUE conjugation (Table 2), which suggested that QUE covalently conjugated with some free amino groups in $\mathrm{OVA}^{20}$. The DPPH and ABTS+ values for OVA conjugates were 2 to 3 times higher than that for unmodified protein, because of more hydroxyl groups in QUE introduced on the protein.

The above results indicate the covalent interaction between QUE and OVA.

\section{Structural analysis of the OVA-QUE conjugates}

Information on changes in the structure of OVA before and after QUE conjugation was obtained by using FTIR and CD spectroscopy and DSC. FTIR 
spectra can help provide information about the changes in the protein secondary structure. The FTIR spectra of samples are in Figure 2A. Protein amide I (1600-1700 $\left.\mathrm{cm}^{-1}\right)$ and amide II $\left(\approx 1530 \mathrm{~cm}^{-1}\right)$ have a relationship with the secondary structure of protein. As compared with native OVA, the peak positions of the amide I band for radical and alkaline OVA-QUE conjugates moved from 1653.08 to 1657.05 and 1651.90, respectively, and peak positions of the amide II band moved from 1537.85 to 1534.83 and 1538.07 , respectively. The results suggested that the secondary structure of the OVA was changed after conjugation with QUE.

CD spectra were used to further analyze the changes in OVA secondary structure after conjugation with QUE. Figure 2B shows that all spectra exhibited a negative band $(222 \mathrm{~nm})$, which is characteristic of $\alpha$-helical structures in protein. As compared with native OVA, the absolute $\theta$ values of this negative band for the conjugates decreased, which indicates loss of some $\alpha$-helical structures in the conjugates ${ }^{19}$. A similar result was obtained previously ${ }^{25}$, with decreased $\alpha$-helical structures of OVA after conjugation with catechin.

The protein structure is related to the thermal stability of the protein. We used DSC to study the thermal stability of the protein. Figure $2 \mathrm{C}$ shows that the thermal denaturation temperatures of OVA and radical and alkaline OVA-QUE conjugates were $98.4,94.9$ and $66.6^{\circ} \mathrm{C}$ respectively, so the tertiary conformation stability of OVA was decreased after covalent conjugation with QUE.

The structural analysis suggested that covalent conjugation with QUE changed the protein secondary structure and caused the unfolded protein structure of OVA. In 
282

283

a previous study, we also found that covalent conjugation with EGCG and chlorogenic acid caused an unfolded OVA structure ${ }^{17-18}$.

\section{In vitro assessment of allergenicity}

The in vitro allergenic capacity of the native OVA and conjugates was analyzed by ELISA to assess the IgE binding capacity. Figure 3A shows a lower IgE binding capacity for OVA after conjugation with QUE. ELISA cannot predict the ability of allergens to trigger degranulation of effector cells ${ }^{24}$. The release of histamine, IL-6 and other cytokines is a characteristic and critical function of basophils ${ }^{26}$. Therefore, we used human basophilic KU812 cells to test the ability of samples to elicit cell degranulation. As compared with native protein, the conjugates showed lower levels of histamine (Figure 3B) and IL-6 (Figure 3C) with conjugation, which suggests that QUE conjugation reduced the ability of OVA to trigger cell degranulation. These results agree with IgE binding capacity testing by ELISA.

\section{In vivo assessment of allergenicity}

A mouse model of orally induced OVA allergy was used to assess the in vivo allergenicity of OVA after conjugation with QUE.

\section{Anaphylactic shock score}

Anaphylactic shock symptoms were observed in BALB/c mice after challenge with native OVA (Figure 4B). However, as compared with native OVA treatment, the 
anaphylactic shock symptoms with both radical and alkaline OVA-QUE conjugate were less severe (Figure 4C), with no significant difference between the radical and alkaline OVA-QUE groups.

Assessment of $\operatorname{IgE}$, $\operatorname{Ig} G, \operatorname{Ig} G 1$, histamine and MCP-1 in mouse serum.

We detected serum-specific IgE, IgG, IgG1, histamine and mMCP-1 in mouse serum to evaluate the allergenic potential of the OVA after conjugation with QUE. As compared with OVA alone, radical and alkaline OVA-QUE conjugate groups showed reduced serum levels of $\operatorname{IgE}$, IgG, IgG1, histamine and mMCP-1 (Figure 4C, 4D, 4E, $4 \mathrm{~F}$ and $4 \mathrm{G})$.

\section{Assessment of cytokines in splenic cells}

Levels of Th2-related cytokines (IL-13, IL-4 and IL-5) and a Th1-related cytokine (IFN- $\gamma$ ) were detected in mouse spleen to further determine whether OVA conjugation with QUE could affect cytokine production in the immune response. As compared with OVA alone, radical and alkaline OVA-QUE conjugate groups showed a marked reduction in IL-13, IL-4 and IL-5 cytokine production in splenic cells, with a slight increase in IFN- $\gamma$ level (Figure 4H, 4I, 4J and 4K).

\section{Histopathological assessment of duodenum}

Histopathological assessment of duodenum is shown in Figure 5. As compared with the control group, in mice sensitized with OVA and OVA-QUE conjugates, the 
intestines were damaged. However, unmodified OVA-treated mice showed more severe allergic symptoms in duodenum than both radical and alkaline OVA-QUE conjugate groups.

\section{$F_{c \varepsilon R I^{+}}$and c-kit ${ }^{+}$expression on peritoneal mast cells}

We collected peritoneal mast cells to test c-kit ${ }^{+}$and $\mathrm{Fc}_{\mathrm{RI}}{ }^{+}$cells by flow cytometry to assess the attenuation of mast cell activation after challenge with OVA and its conjugates. The proportion of $\mathrm{c}-\mathrm{kit}^{+}$and $\mathrm{Fc \varepsilon RI} \mathrm{I}^{+}$cells was greater with OVA challenge than control treatment and radical and alkaline OVA-QUE treatment (Figure 6).

Changes in the allergenicity of food allergen by conjugation with dietary polyphenols have been reported; however, research on the effect in vivo remains unclear. In this study, we evaluated the effect of QUE conjugation with OVA on sensitization and the allergic response in a $\mathrm{BALB} / \mathrm{c}$ mouse model. On in vivo assessment of allergenicity in BALB/c mice, different levels of allergic symptoms were triggered by OVA and its conjugates, which suggests lower allergenicity in vivo with OVA-QUE conjugates than the native protein.

After conjugation with QUE, OVA relieved anaphylactic symptoms in mice. As compared with native OVA, histamine secretion with OVA-QUE treatment was reduced, which was consistent with the in vitro study. The IgE binding capacity of an allergen is directly related to its IgE binding epitopes. Conjugation with QUE alters OVA structures, then affects the conformational epitopes of the protein. Furthermore, 
in our previous studies, we found that polyphenols conjugated on the surface of the protein, which might affect linear IgE epitopes ${ }^{17-18}$. Therefore, after conjugation with QUE, conformational and linear IgE epitopes in OVA may have been affected, thereby reducing the IgE binding capacity, then led to decreased release of histamine. Histamine will be released from basophil degranulation and mast cells and then induce an allergic reaction ${ }^{27}$.

Our OVA-QUE conjugates induced histamine significantly less than did the native protein, which may be related to the weak systemic allergic symptoms. $\mathrm{Fc \varepsilon RI}^{+}$and c-kit ${ }^{+}$were expressed on the surface of sensitized mast cells. Flow cytometry revealed significantly higher expression of c-kit ${ }^{+}$and $\mathrm{Fc}_{\mathrm{R}} \mathrm{RI}^{+}$in OVA-challenged mice than in controls, with the expression significantly reduced in the OVA-QUE conjugate groups.

The level of mMCP-1 is key indicator for detecting mastocyte degranulation. The level of mMCP-1 was higher in OVA-challenged mice than controls. As compared with OVA challenge, with OVA-QUE conjugate challenge, the level of mMCP-1 was significantly reduced. The results of mMCP-1 measurement were consistent in the results of $\mathrm{Fc \varepsilon RI}{ }^{+}$and c-kit ${ }^{+}$detection, which illustrates that after conjugation with QUE, mastocyte degranulation was alleviated, thereby reducing the allergenicity of OVA.

IFN- $\gamma$ secreted by Th1 cells can inhibit IgE production ${ }^{28}$. However, cytokines including IL-13, IL-4, and IL-5 can provoke Th2 cells to produce IgE and induce an IgG isotype switch to IgG1. IgG1 and IgE can induce systemic anaphylaxis ${ }^{29}$ and 
Th2-dependent antibodies ${ }^{30}$. In this study, as compared with serum from native OVA challenge, that from OVA-QUE challenge showed significantly reduced levels of IgE and IgG1.

Moreover, conjugation with QUE downregulated the Th2-related cytokines (IL-13, IL-4 and IL-5) in spleen cells but upregulated the Th1 cytokine (IFN- $\gamma$ ), which agreed with the detection of antibodies in mice. Thus, conjugation with QUE may have suppressed the OVA allergic reaction by modulating the Th1/Th2 imbalance: suppressing Th2 immune response and promoting the Th1 immune response.

We prepared OVA-QUE conjugates by radical and alkaline methods. The mechanisms of these two methods are different. In the free radical method, hydroxide radicals are generated by oxidation-deduction reactions between redox pair components, then the radicals attack the amino acid in protein to produce radical species, which react with polyphenols, inducing a covalent bond ${ }^{31}$. In the alkaline method, polyphenols are oxidized to form a semiquinone, which may react with some residues such as histidine, cysteine and lysine residues in the chains of the protein to form a covalent bond ${ }^{31}$. However, the allergenicity of the radical and alkaline OVAQUE conjugates did not significantly differ. Thus, both radical and alkaline methods could be used to prepare OVA-QUE conjugates with weaker allergenicity than native OVA. The weaker allergenicity of OVA-QUE conjugates may be due to QUE destroying and/or masking OVA epitopes. To our knowledge, the interaction of polyphenols with proteins can alter the immunological properties of protein by changing the protein structure and/or masking 
392

393

epitopes and their direct effect on allergic effector cells ${ }^{4}$. In addition, their endogenous antioxidant ability limits the extent of cellular injury from free radicals during the allergic insult ${ }^{4}$. Some polyphenols show inhibitory properties against some digestive enzymes, such as pepsin, which would affect the digestibility of food allergens ${ }^{32}$. In most cases, in the preparation of non-covalent protein-polyphenol complexes, the unreacted polyphenols are not removed, and the polyphenols binding on the protein may be released under certain conditions. So, the free polyphenols in the non-covalent protein-polyphenol complex may have an important anti-allergy role.

QUE has been investigated for its anti-allergic effect in different disease models ${ }^{33-35}$. In this study, unreacted QUE was removed by dialysis. Furthermore, the proteinpolyphenol covalent conjugate was more stable than the non-covalent proteinpolyphenol complex. The QUE binding on the covalent conjugate hardly moved away from the conjugate. Therefore, there was no free QUE in the test samples, which may not directly affect the immune cell and biological pathways in the allergic immune response by the free QUE. Whether QUE covalent binding on the protein has the same anti-allergic effect as free QUE deserves further investigation.

In conclusion, QUE could covalently conjugate with OVA and led to a changed protein structure of OVA, which might destroy and/or mask OVA epitopes. The conjugates showed lower allergenicity in vitro and in vivo. Conjugation with QUE reduced the ability for IgE binding and triggering cell degranulation of OVA in vitro, and the levels of specific IgE, IgG1, IgG, plasma histamine, and mMCP-1 as well as 
$414 \mathrm{FceRI}^{+}$and c-kit ${ }^{+}$expression on the surface of sensitized mast cells were suppressed.

415 Furthermore, conjugation with QUE modulated the imbalance of the Th1/Th2

416 immune response, which might suppress the OVA-induced allergic reaction.

417 Therefore, conjugation OVA with QUE could reduce OVA allergenicity, which may 418 help in producing hypoallergenic food.

\section{$420 \quad$ Funding}

421 This study was supported in part by the Research Funding for Innovation Project

422 of Universities in Guangdong Province (2018KTSCX192), Key-Area Research and

423 Development Program of Guangdong Province (2019B020213001), Medical

424 Technological Research Funding of Guangdong Province (B2018041) and Research

425 Funding of Shenzhen (JCYJ20170818143841444 and JCYJ201803053000708). 


\section{References}

(1) Sicherer, S. H.; Sampson, H. A. Food allergy: Epidemiology, pathogenesis, diagnosis, and treatment. J. Allergy Clin. Immun. 2014, 133, 291-307.

(2) Benhamou, A. H.; Caubet, J. C.; Eigenmann, P. A.; Nowak-Wegrzyn, A.; Marcos, C. P.; Reche, M.; Urisu, A. State of the art and new horizons in the diagnosis and management of egg allergy. Allergy 2010, 65, 283-289.

(3) Abeyrathne, E. D. N. S.; Lee, H. Y.; Ahn, D. U. Egg white proteins and their potential use in food processing or as nutraceutical and pharmaceutical agents--a review. Poultry Sci. 2013, 92, 3292-3299.

(4) Singh, A.; Holvoet, S.; Mercenier, A. Dietary polyphenols in the prevention and treatment of allergic diseases. Clinical \& Experimental Allergy 2011, 41, 1346-1359.

(5) Liu, F.; Ma, C.; McClements, D. J.; Gao, Y. A comparative study of covalent and non-covalent interactions between zein and polyphenols in ethanol-water solution. Food Hydrocolloid. 2017, 63, 625-634.

(6) Ozdal, T.; Capanoglu, E.; Altay, F. A review on protein - phenolic interactions and associated changes. Food Res. Int. 2013, 51, 954-970.

(7) Pérot, M.; Lupi, R.; Guyot, S.; Delayre-Orthez, C.; Gadonna-Widehem, P.; Thébaudin, J.; Bodinier, M.; Larré, C. Polyphenol interactions mitigate the immunogenicity and allergenicity of gliadins. J. Agr. Food Chem. 2017, 65, 6442-6451.

(8) Chung, S.; Champagne, E. T. Reducing the allergenic capacity of peanut extracts and liquid peanut butter by phenolic compounds. Food Chem. 2009, 115, 1345-1349.

(9) Gruber, P.; Vieths, S.; Wangorsch, A.; Nerkamp, J. Maillard Reaction and Enzymatic Browning Affect the Allergenicity of Pru av 1, the Major Allergen from Cherry (Prunus avium. Journal of Agricuture and Food Chemistry 2004, 12, 4002-4007.

(10) Bansode, R. R.; Plundrich, N. J.; Randolph, P. D.; Lila, M. A.; Williams, L. L. Peanut flour aggregation with polyphenolic extracts derived from peanut skin inhibits IgE binding capacity and attenuates RBL-2H3 cells degranulation via MAPK signaling pathway. Food Chem. 2018, 263, 307-314.

(11) Plundrich, N. J.; White, B. L.; Dean, L. L.; Davis, J. P.; Foegeding, E. A.; Lila, M. A. Stability and immunogenicity of hypoallergenic peanut protein-polyphenol complexes during in vitro pepsin digestion. Food Funct. 2015, 6, 2145-2154.

(12) Plundrich, N. J.; Bansode, R. R.; Foegeding, E. A.; Williams, L. L.; Lila, M. A. Protein-bound Vaccinium fruit polyphenols decrease IgE binding to peanut allergens and RBL-2H3 mast cell degranulation in vitro. Food Funct. 2017, 8, 1611-1621.

(13) Bansode, R. R.; Randolph, P. D.; Plundrich, N. J.; Lila, M. A.; Williams, L. L. Peanut protein-polyphenol aggregate complexation suppresses allergic sensitization to peanut by reducing peanut-specific IgE in C3H/HeJ mice. Food Chem. 2019, 299, 125025.

(14) Wu, X.; Zhong, X.; Liu, M.; Xia, L.; Feng, K.; Wu, H.; Liu, Z. Reduced allergenicity of $\beta$ -lactoglobulin in vitro by tea catechins binding. Food Agr. Immunol. 2013, 24, 305-313.

(15) Ognjenović, J.; Stojadinović, M.; Milčić, M.; Apostolović, D.; Vesić, J.; Stambolić, I.; Atanasković-Marković, M.; Simonović, M.; Velickovic, T. C. Interactions of epigallo-catechin 3-gallate and ovalbumin, the major allergen of egg white. Food Chem. 2014, 164, 36-43. 
(16) Ozdal, T.; Capanoglu, E.; Altay, F. A review on protein - phenolic interactions and associated changes. Food Res. Int. 2013, 51, 954-970.

(17) Lu, Y.; Li, S.; Xu, H.; Zhang, T.; Lin, X.; Wu, X. Effect of Covalent Interaction with Chlorogenic Acid on the Allergenic Capacity of Ovalbumin. J. Agr. Food Chem. 2018, 66, 9794-9800.

(18) He, W.; Xu, H.; Lu, Y.; Zhang, T.; Li, S.; Lin, X.; Xu, B.; Wu, X. Function, digestibility and allergenicity assessment of ovalbumin - EGCG conjugates. J. Funct. Foods 2019, 61, 103490.

(19) Wu, X.; Lu, Y.; Xu, H.; Lin, D.; He, Z.; Wu, H.; Liu, L.; Wang, Z. Reducing the allergenic capacity of $\beta$-lactoglobulin by covalent conjugation with dietary polyphenols. Food Chem. 2018, 256, 427-434.

(20) Xu, H.; Zhang, T.; Lu, Y.; Lin, X.; Hu, X.; Liu, L.; He, Z.; Wu, X. Effect of chlorogenic acid covalent conjugation on the allergenicity, digestibility and functional properties of whey protein. Food Chem. 2019, 298, 125024.

(21) Rawel, H. M.; Rohn, S.; Kruse, H. P.; Kroll, J. Structural changes induced in bovine serum albumin by covalent attachment of chlorogenic acid. 2002, 443-455.

(22) He, W.; Xu, H.; Lu, Y.; Zhang, T.; Li, S.; Lin, X.; Xu, B.; Wu, X. Function, digestibility and allergenicity assessment of ovalbumin - EGCG conjugates. J. Funct. Foods 2019, 61, 103490.

(23) Wu, X.; Liu, M.; Xia, L.; Wu, H.; Liu, Z.; Xu, X. Conjugation of functional oligosaccharides reduced in vitro allergenicity of $\beta$-lactoglobulin. Food Agr. Immunol. 2013, 24, 379-391.

(24) Zhang, Y.; Wu, Z.; Li, K.; Li, X.; Yang, A.; Tong, P.; Chen, H. Allergenicity assessment on thermally processed peanut influenced by extraction and assessment methods. Food Chem. 2019, 281, 130-139.

(25) Feng, J.; Cai, H.; Wang, H.; Li, C.; Liu, S. Improved oxidative stability of fish oil emulsion by grafted ovalbumin-catechin conjugates. Food Chem. 2018, 241, 60-69.

(26) MacGlashan, D. W. Basophil activation testing. J. Allergy Clin. Immun. 2013, 132, 777-787.

(27) Manuyakorn, W.; Tanpowpong, P. Cow milk protein allergy and other common food allergies and intolerances. Paediatr Int Child Health 2019, 39, 32-40.

(28) Burton, O. T.; Medina, T. J.; Stranks, A. J.; Miller, S.; Koleoglou, K. J.; Weinberg, E. O.; Oettgen, H. C. IgE promotes type 2 innate lymphoid cells in murine food allergy. Clin. Exp. Allergy 2018, 48, 288-296.

(29) K, S.; R, T.; E, I.; K, T.; H, Y.; T, S.; S, H.; S, H.; S, K. Lactobacillus casei strain Shirota suppresses serum immunoglobulin $\mathrm{E}$ and immunoglobulin $\mathrm{G} 1$ responses and systemic anaphylaxis in a food allergy model. Clinical \& Experimental Allergy 2002, 32, 563-570.

(30) Shi, C.; Pan, T.; Cao, M.; Liu, Q.; Zhang, L.; Liu, G. Suppression of Th2 immune responses by the sulfated polysaccharide from Porphyra haitanensis in tropomyosin-sensitized mice. Int. Immunopharmacol. 2015, 24, 211-218.

(31) Rohn, S. Possibilities and limitations in the analysis of covalent interactions between phenolic compounds and proteins. Food Res. Int. 2014, 65, 13-19.

(32) Podsędek, A.; Majewska, I.; Redzynia, M.; Sosnowska, D.; Koziołkiewicz, M. In vitro inhibitory effect on digestive enzymes and antioxidant potential of commonly consumed fruits. J. Agr. Food Chem. 2014, 62, 4610-4617.

(33) Escribano-Ferrer, E.; Queralt Regué, J.; Garcia-Sala, X.; Boix Montañés, A.; Lamuela-Raventos, R. M. In vivo anti-inflammatory and antiallergic activity of pure naringenin, naringenin chalcone, and quercetin in mice. J. Nat. Prod. 2019, 82, 177-182.

(34) Rogerio, A. P.; Kanashiro, A.; Fontanari, C.; Da Silva, E. V. G.; Lucisano-Valim, Y. M.; Soares, 
E. G.; Faccioli, L. H. Anti-inflammatory activity of quercetin and isoquercitrin in experimental murine allergic asthma. Inflamm. Res. 2007, 56, 402-408.

(35) Wang, B.; Hui, Y.; Liu, L.; Zhao, A.; Chiou, Y.; Zhang, F.; Pan, M. Optimized extraction of phenolics from Jujube peel and their anti-inflammatory effects in LPS-stimulated murine macrophages. J. Agr. Food Chem. 2019, 67, 1666-1673. 


\section{Figure Legends}

Figure 1. SDS-PAGE analysis of OVA and OVA-QUE conjugates.

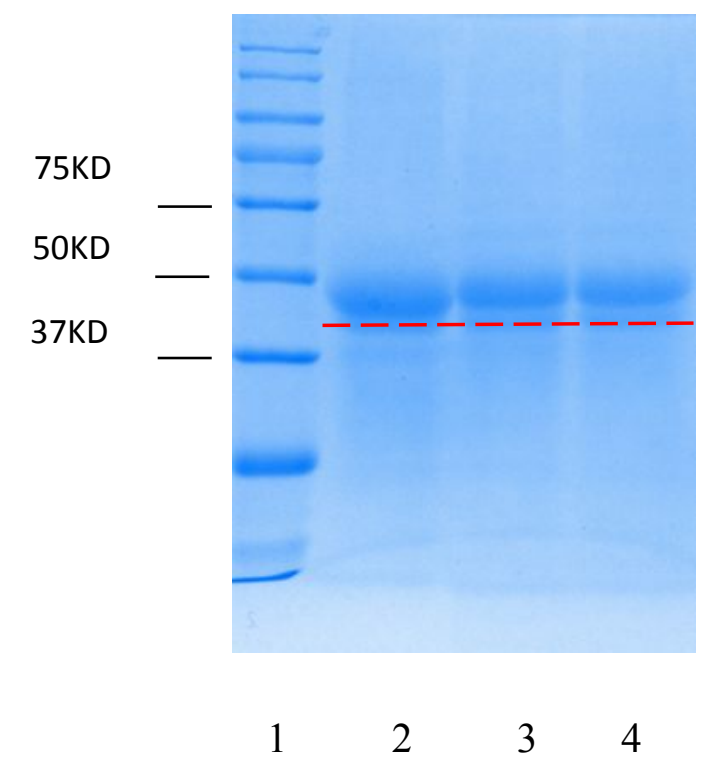

1: Marker, 2: Native OVA, 3: Radical OVA-QUE conjugate, 4: Alkaline OVA-QUE conjugate 
Figure 2. Fluorescence (A), CD (B) and DSC (C) spectra for OVA and OVA-QUE conjugates.

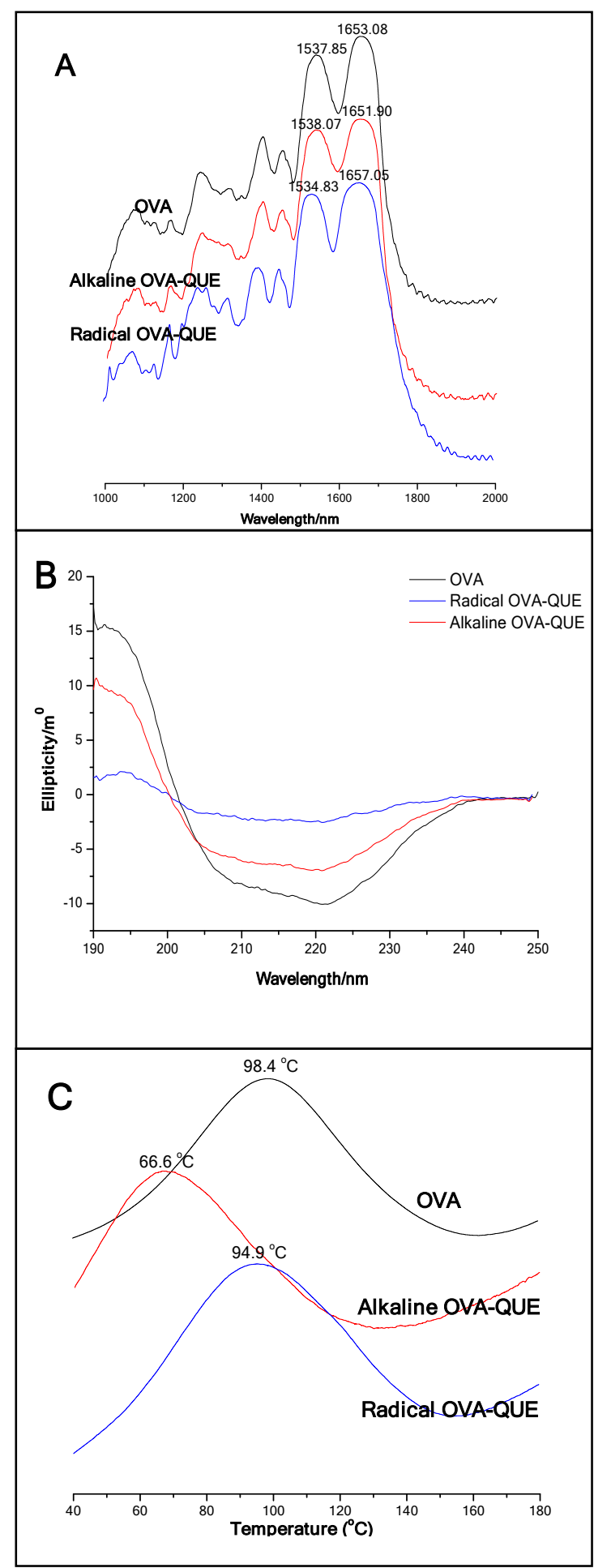


Figure 3. IgE binding ability detected by ELISA (A), basophil histamine release with KU812 cell degranulation (B) and IL-4 release with KU812 cell degranulation (C) with OVA or radical or alkaline OVA-QUE conjugates.

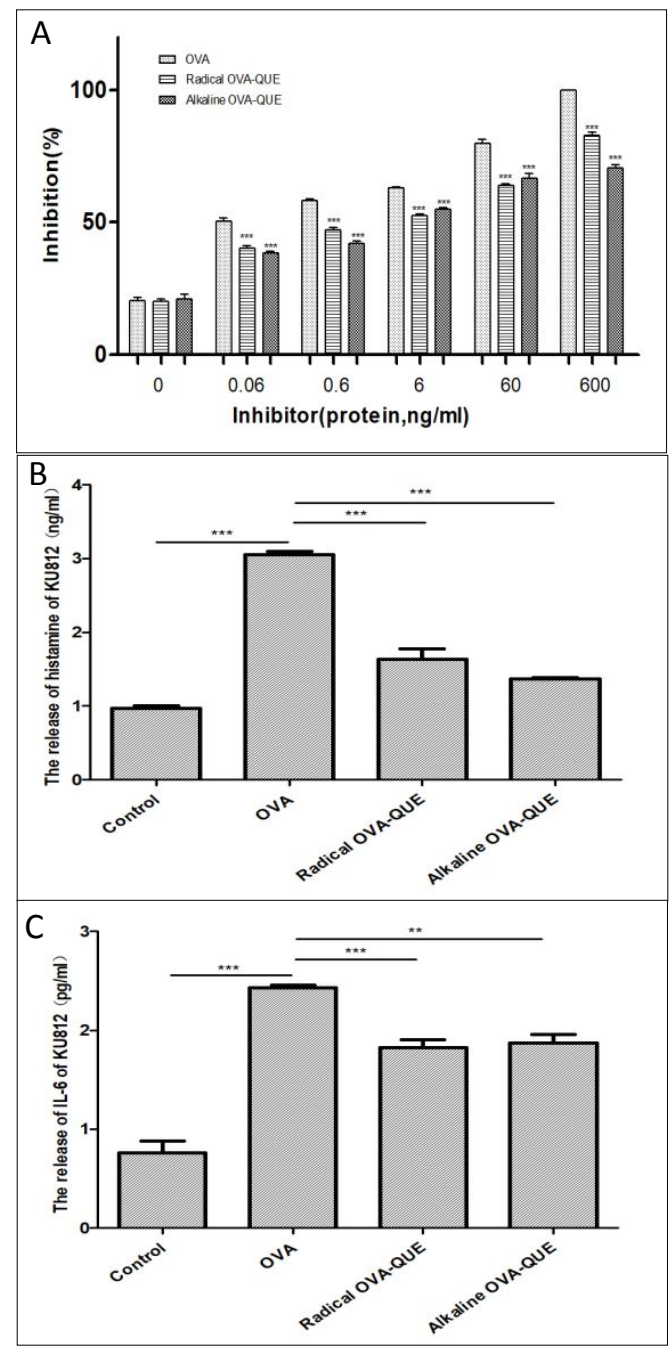




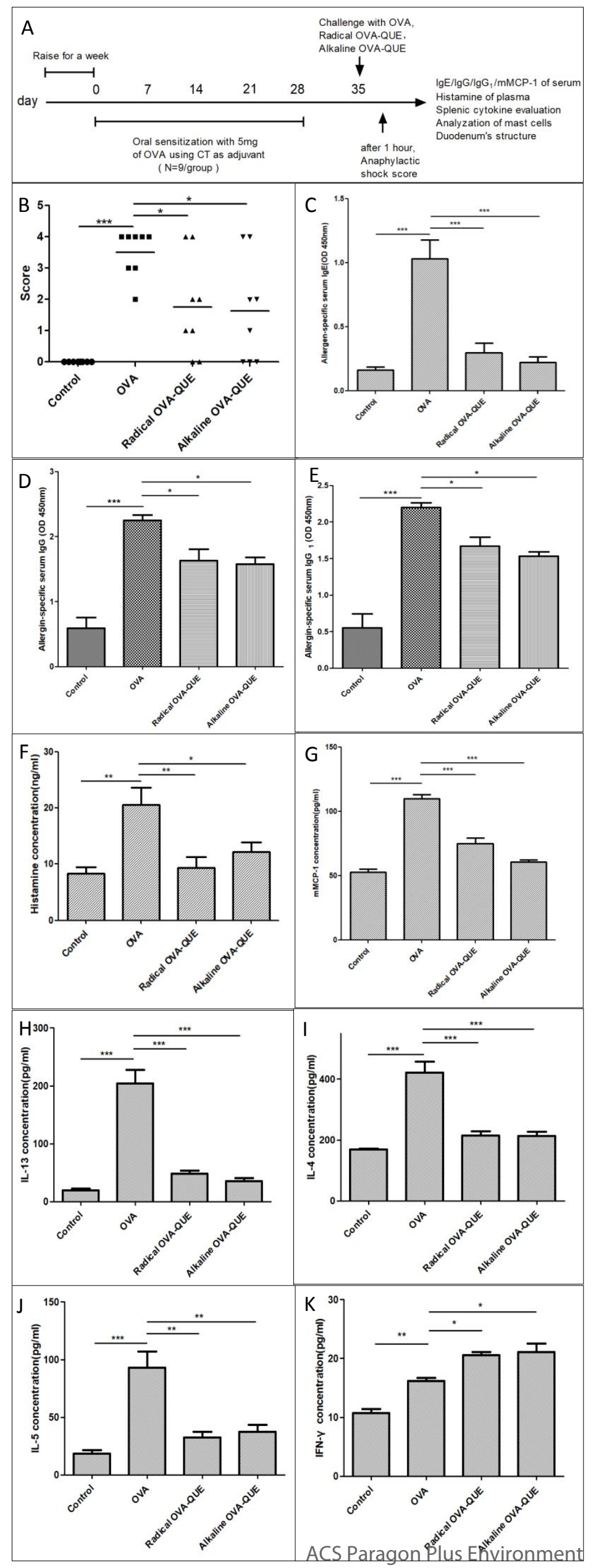

Figure 4. Oral immunization of BALB/c mice with OVA or radical or alkaline OVA-QUE conjugates (A). Hypersensitivity symptoms scored on a scale from 0 (no symptoms) to 5 (death) as described in Table 1. Levels of IgG (C), IgG1 (D), IgE (E), plasma histamine (F) and mMCP-1 (G) in serum from mice. Levels of cytokines IL-13 (H), IL-4 (I), IL-5 (J) and $\gamma$-IFN (K) in mouse spleen. Results are expressed as mean \pm SD. $* * * \mathrm{p}<0.001, * * \mathrm{P}<$ $0.01,{ }^{*} \mathrm{P}<0.05$ compared with OVA group. 
Figure 5. Effects of control (A), OVA (B), radical OVA-QUE (B) and alkaline OVA-QUE (D) treatment on morphological structure of duodenum in mice.

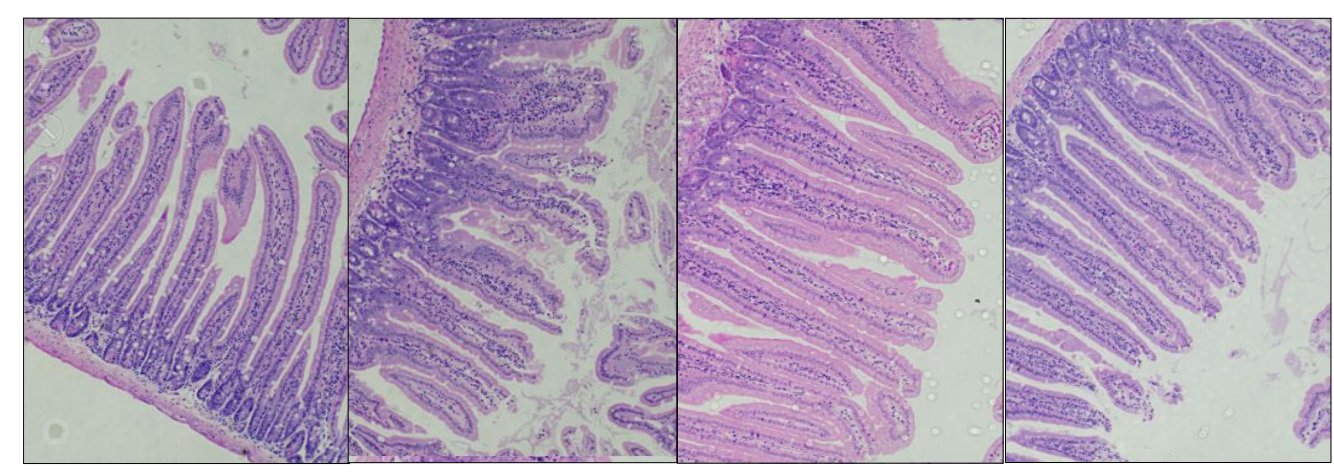


Figure 6. FceRI and c-kit expression on peritoneal mast cells with control (A), OVA (B), radical OVA-QUE (B) and OVA-QUE (D) treatment. The proportion of FceRI and c-kit cells was quantified (E). ${ }^{* * *} \mathrm{p}<0.001,{ }^{*} \mathrm{P}<0.01, * \mathrm{P}<0.05$ significant difference as compared with the OVA group.

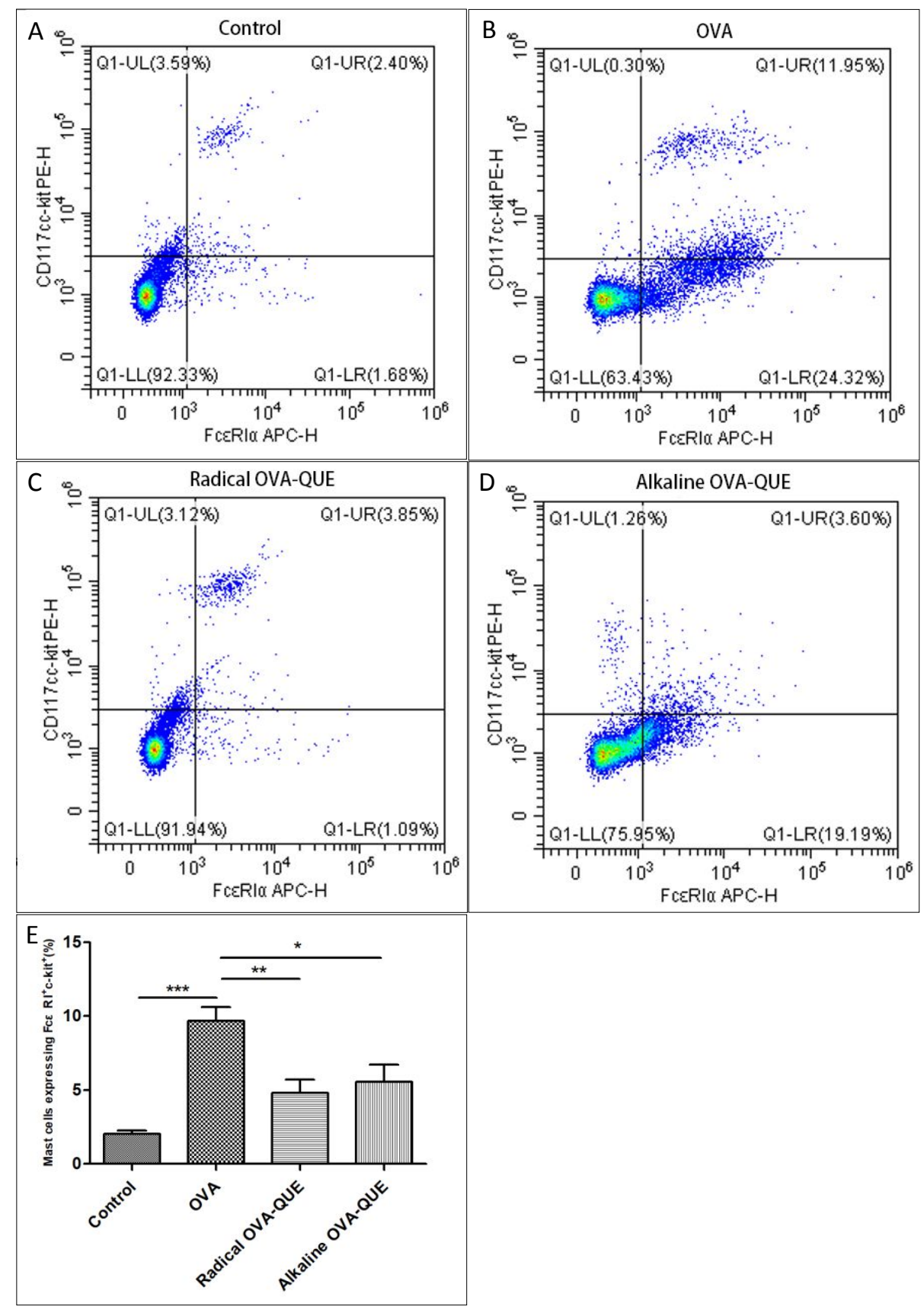




\section{Tables}

Table 1. Anaphylactic symptom scoring

Score Symptoms

$0 \quad$ No symptoms

1 Scratching nose and mouth

2 Swelling around the eyes and mouth; pillar erection; reduced activity; higher breathing rate

3 Shortness of breath; blue rash around the mouth and tail; higher breaching rate

$4 \quad$ No activity after stimulation, shivering and muscle contractions

5 Death by shock 
Table 2. Characterization of OVA and OVA-QUE conjugates.

\begin{tabular}{cccc}
\hline Protein/sample & $\begin{array}{c}\text { Native } \\
\text { OVA }\end{array}$ & $\begin{array}{c}\text { Radical } \\
\text { OVA-QUE }\end{array}$ & $\begin{array}{c}\text { Alkaline } \\
\text { OVA-QUE }\end{array}$ \\
\hline Polyphones bound $(\mathrm{mg} / \mathrm{g})$ & - & $38.61 \pm 2.10^{* * *}$ & $21.55 \pm 1.91^{* * *}$ \\
Free amino group $(\mathrm{nmol} / \mathrm{mg})$ & $1.17 \pm 0.007$ & $0.64 \pm 0.017^{* * *}$ & $0.92 \pm 0.003^{* * *}$ \\
& & & \\
Thiol group $(\mathrm{nmol} / \mathrm{mg})$ & $3.08 \pm 0.104$ & $2.76 \pm 0.061^{*}$ & $1.56 \pm 0.070^{* *}$ \\
& & & \\
DPPH scavenging activity & $1.53 \pm 0.1996$ & $5.27 \pm 0.085^{* * *}$ & $4.88 \pm 0.028^{* * *}$ \\
$(\mu \mathrm{mol}$ Trolox $/ \mathrm{g}$ sample $)$ & & & $6.84 \pm 0.214^{* * *}$ \\
ABTS+ scavenging activity & $3.24 \pm 0.146$ & $6.44 \pm 0.600^{* *}$ & \\
$(\mu \mathrm{mol}$ Trolox $/ \mathrm{g}$ sample $)$ & & &
\end{tabular}

$* * * \mathrm{p}<0.001, * * \mathrm{P}<0.01, * \mathrm{P}<0.05$ significant difference as compared with the native OVA. 


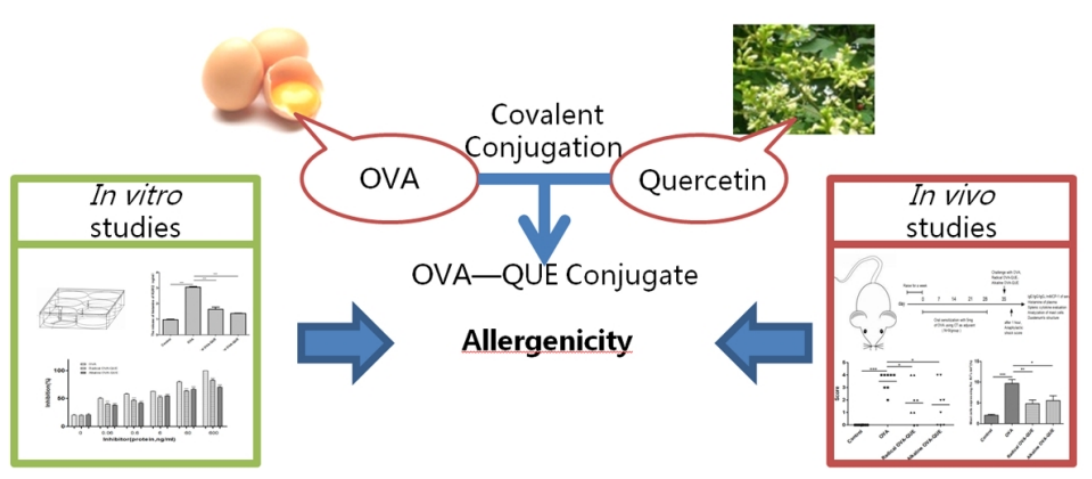

$119 \times 45 \mathrm{~mm}(300 \times 300 \mathrm{DPI})$ 